Reprinted by permission of the American Society of Law, Medicine and Ethics, ( 2005.

\title{
Dying in America- An Examination of Policies that Deter Adequate END-OF-LIFE CARE IN NURSING HoMES
}

Diane E. Hoffmann, J.D., M.S.

Anita J. Tarzian, Ph.D., R.N. 


\title{
Dying in America- An Examination of Policies that Deter Adequate END-OF-LIFE CARE IN NURSING HOMES*
}

\begin{abstract}
AUTHORS
Diane E. Hoffmann, J.D., M.S., is Professor of Law, Associate Dean for Academic Programs and Director of the Law \& Health Care Program at the University of Maryland School of Law. She received her J.D. from Harvard Law School and her master's degree, in Health Policy \& Management, from the Harvard School of Public Health.
\end{abstract}

Anita J. Tarzian, Ph.D., R.N., is Research Associate for the Law \& Health Care Program at the University of Maryland School of Law and an independent consultant in research and ethics. She received a Ph.D. in Nursing and Ethics and an M.S. in Intercultural Nursing from the University of Maryland School of Nursing.

\begin{abstract}
This article examines current health care policies and government practices that deter appropriate end-of-life care, focusing on the use of hospice services for dying nursing home patients. The authors conclude that hospice and nursing home regulations, reimbursement for hospice and nursing homes, and enforcement of the fraud and abuse rules collude to "chill" utilization of hospice by nursing homes and result in inadequate end-of-life care for many nursing home patients. They argue that these policies and practices have at their roots a number of questionable assumptions and call for a shift in existing paradigms affecting care to this group and a realigning of incentives among these various government policies to achieve consistent policy goals.
\end{abstract}

*This paper is an outgrowth of two empirical studies one funded by the Borchard Foundation on Law and Aging and the other by the Donaghue Medical Research Foundation. It is being published in a forthcoming issue of the Journal of Law, Medicine \& Ethics. 


\section{Dying in America- An Examination of Policies that Deter Adequate END-OF-LIFE CARE IN NURSING HoMES}

\section{INTRODUCTION}

The quality of end-of-life care in this country is often poor. There is abundant literature indicating that dying individuals do not receive adequate pain medication or palliative care, are tethered to machines and tubes in a way that challenges their dignity and autonomy, and are not helped to deal with the emotional grief and psychological angst that may accompany the dying process. While this is true for individuals in many settings, it seems to be especially true for individuals in nursing homes. This is somewhat puzzling given that (1) considerable resources have been devoted to bringing public attention to this problem, (2) we have the knowledge and expertise to provide such care, and (3) we have a government-financed benefit that covers this type of care - the Medicare hospice benefit (MHB).

While utilization of hospice care has increased during the last decade, there is considerable evidence that hospice care remains underutilized particularly in the long term care setting. There are a host of reasons for the lack of utilization, some are cultural and attitudinal, some are based on a lack of awareness of the benefit, but others are arguably a result of government policies and practices. These policies, particularly at the federal level, systematically collude to inhibit adequate hospice care for dying nursing home patients. In this article we examine the adverse, but largely unintended, consequences of these government policies and practices, which include current Medicare regulations defining hospice eligibility and the type of care that must be provided to nursing home residents, reimbursement for both hospice and nursing home care, and the initiatives of the Office of the Inspector General (OIG) to combat fraud in this area. We assert that at root these policies and practices are based on questionable assumptions about such issues as where people die, the predictability of death, and the financial 
incentives of nursing homes to utilize hospice. As a result, we call for a shift in a number of

paradigms that have affected policies related to caring for nursing homes residents at the end-of-

life. These include a shift from a singular focus on rehabilitation of nursing home patients to one that encompasses palliation, and a change from viewing dying as a well defined event to viewing dying as a process. We further argue that enforcers concerned about fraud and abuse in this context need to temper an exclusive focus on deterrence of "over utilization" of services to one that acknowledges underutilization. The result is that we need to reframe our policies and practices in this area, realign the incentives for providers, and find the right balance in each of these dyads.

\section{BACKGROUND}

\section{Hospice Utilization in Nursing Homes}

While nationally between $18 \%$ and $23 \%$ of all elderly people who die are enrolled in hospice, ${ }^{1}$ numerous studies have shown that terminally ill residents of nursing homes have been less likely to receive hospice services than individuals residing in their homes. ${ }^{2}$ Zerzan et al., in a 2000 article published in the Journal of the American Medical Association, reported that although "similar numbers of Medicare beneficiaries die in nursing homes and in private homes . . those who die at home are more likely to receive hospice care."3 Although the percentage of

\footnotetext{
${ }^{1}$ See Barbara Gage et Al., DHHS, Important Questions for Hospice In the NeXT Century 1 (Mar. 2000), available at $\mathrm{http} / / / \mathrm{www}$. aspe.hhs.gov/daltcp/reports/impques.pdf (stating that "[a]lmost 18 percent of all elderly people who die are enrolled in hospice."); see also LAST ACTS, MEANS TO A BETTER END: A REPORT ON DYING IN AMERICA TODAY 16, at http://www.rwjf.org/news/special/meansReport.pdf (Nov. 2002); Diane E. Campbell et al., Medicare Program Expenditures Associated with Hospice Use, 140 ANNALS InTERnAL MED. 269, 269 (2004) (stating that enrollment in the "Medicare hospice benefit increased from 9\% in 1992 to 23\% in 2000.").

${ }^{2}$ A national study published in 1999 found that only $1 \%$ of nursing home patients were enrolled in hospice at any one time and that $70 \%$ of homes had no hospice patients enrolled. See Ann C. Petrisek \& Vincent Mor, Hospice in Nursing Homes: A Facility-Level Analysis of the Distribution of Hospice Beneficiaries, 39 Gerontologist 279 (1999); see also Davina Porock et al., A Profile of Residents Admitted to Long-Term Care Facilities for End-of-Life Care, 4 J. Am. Med. Directors Ass'N 16 (2003) (finding that in Missouri in 1999 only 30\% of certified long term care facilities in the state provided hospice care to their residents).

${ }^{3}$ Judy Zerzan et al., Access to Palliative Care and Hospice in Nursing Homes, 284 J. AM. Med. Ass'N 2489 (2000). The observation is based on North Carolina hospice data which found that in that state in 1997, 19\% of deaths occurred in nursing homes and $22 \%$ in private homes but that during that year "only $13 \%$ of hospice enrollees were in nursing homes, while $87 \%$ were in private homes." See North CAROLINA Division OF FACILITY SERVS.,
} 
hospice enrollees in nursing facilities has increased significantly over the last few years, ${ }^{4}$ several

sources indicate that hospice services remain underutilized in the nursing home setting and that dying nursing home patients often do not receive adequate or appropriate end-of-life care. ${ }^{5}$

Moreover, there are data in some states indicating that nursing homes may not accurately

identify residents with end-of-life care needs and that those residents designated with such needs

may not receive hospice care. ${ }^{6}$ In addition, several recent studies have found that the hospice

average length of stay is shorter for patients with certain diagnoses that are more common in nursing home patients. ${ }^{7}$

ANNuAl Hospice Licensure Data SuPPLEMENT, 1997 (1997). Year 2000 data from the National Center for Health Statistics indicated a similar utilization pattern at the national level. Of all deaths in $2000,22 \%$ were in nursing homes and $22.7 \%$ were in private residences. Of all deaths in that year of individuals 65 and older, $28.1 \%$ were in nursing homes and $21.2 \%$ were in a private residence. NAT'L CTR. FOR HEALTH STATISTICS, DHHS, TABLE 309. Deaths by Place of Death, Age, Race, AND SeX: United States, 2000, at

http://www.cdc.gov/nchs/data/statab/mortfinal2000_work309.pdf (Mar. 21, 2003). Of those enrolled in hospice in $2000,77 \%$ were in private residences and $18 \%$ were in health facilities (nursing home, hospital or other inpatient facility). NAT'L Ctr. For HeAlth Statistics, DHHS, TABle 1. Number, PERCENT Distribution, AND RATE PER 100,000 POPULATION OF HOSPICE CARE DISCHARGES BY AGE, ACCORDING TO SEX, RACE, AND REGION: UNITED STATES, 2000, at http://www.cdc.gov/nchs/about/major/nhhcsd/homecare2.htm\#hospice (Feb. 2004). Year 2002 data from the National Hospice and Palliative Care Organization (NHPCO) confirm these earlier findings. NHPCO reports that in 2002 about $25 \%$ of deaths occurred at home and $25 \%$ occurred in a nursing facility. In that same year, of those served by hospice, $57.9 \%$ died at home and $21.5 \%$ died in a nursing facility. NHPCO Facts \& Figures at www.nhpco.org/files/public/Facts\%20Figures\%20Feb04.pdf (last updated Feb. 2004).

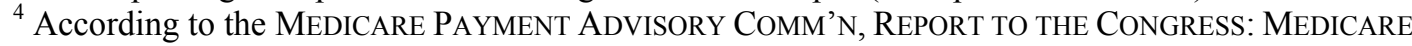
BENEFICIARIES' ACCESS TO HOSPICE 5, at http://www.medpac.gov/publications/congressional_reports/may2002_HospiceAccess.pdf (May 2002), the percentage of hospice enrollees in nursing homes increased from $11 \%$ in 1992 to $36 \%$ in 2000 . However, according to the NHPCO, in 2002, $21.5 \%$ of hospice patients died in a nursing home. See NHPCO Facts \& Figures, supra note 3. Yet, a more recent study by Campbell et al., supra note 1, indicated that $45 \%$ of hospice patients were nursing home residents. The exact percentage of hospice enrollees in nursing homes is not readily available as this information is not routinely collected as part of Medicare administrative data.

${ }^{5}$ See Terrie Wetle et al., End-of-life in Nursing Homes: Experiences and Policy Recommendations, a report prepared for AARP (forthcoming) (manuscript on file with authors); see also Robert J. Buchanan et al., End-of-Life Care in Nursing Homes: Residents in Hospice Compared to Other End-Stage Residents, 7 J. PaLliative MED. 221 (2004); Debra Parker-Oliver et al., End-of-Life Care in U.S. Nursing Homes: A Review of the Evidence, 5 J. AM. MED. DireCtors Ass'N 147 (2004); Mary Beth Happ et al., Advance Care Planning and End-of-life Care for Hospitalized Nursing Home Residents, 50 J. AM. GERIATRICS SOC'Y 829 (2002).

${ }^{6}$ See Debra Parker-Oliver et al., Hospice and Nonhospice Nursing Home Residents, 6 J. PALLIATIVE MED. 69 (2003).

${ }^{7}$ See Medicare Payment AdVISORY Comm'N, supra note 4, at 6 (stating that certain diagnoses, such as congestive heart failure and myocardial infarction, "significantly predicted admission to hospice within two weeks of death"); see also Campbell et al., supra note1, at 274 (stating that "entry to hospice in the last week of life was more prevalent among enrollees without cancer than those with cancer" 36\% v. 23\%); Susan C. Miller et al., Hospice Length of Stay in Nursing Homes and Factors Influencing Short Stays, 40 GERONTOLOGIST 302 (2002) (finding that in nursing homes, residents with dementia and diagnoses other than cancer or dementia were found to have hospice lengths of stay of one week or less.) 


\section{Structure of the Benefit}

The hospice philosophy embraces a holistic approach to support individuals and families at the end-of-life, providing physical pain and symptom management as well as psychological and spiritual support from a team of volunteers and health care professionals. To be eligible for the MHB, the patient's physician and the hospice medical director or a physician member of the hospice interdisciplinary team must certify that the patient is terminally ill ${ }^{8}$ (with a life expectancy of six months or less ${ }^{9}$ if the disease "runs its normal course." ${ }^{10}$ After the first 90 day period, the second 90 day period, and for every 60 day period thereafter that the patient remains in hospice, one of the hospice physicians must certify that the patient is terminally ill. ${ }^{11}$ A patient may remain in hospice for an unlimited number of 60 day periods as long as the hospice physician certifies that he or she is terminally ill. ${ }^{12}$ Individuals who elect the MHB also waive coverage of all Medicare funded curative care related to the patient's terminal illness as well as care that would be duplicative of hospice care. ${ }^{13}$ Medicare will continue to pay, however, for a beneficiary's covered medical needs unrelated to the terminal condition. ${ }^{14}$

\footnotetext{
${ }^{8}$ See 42 U.S.C.A. § 1395f(a)(7) (West Supp. 2004).

${ }^{9}$ See 42 U.S.C.A. $\S 1395 x(\mathrm{dd})(3)(A)$ (West Supp. 2004).

${ }^{10} 42$ C.F.R. $\S 418.22$ (b) (2003).

${ }^{11}$ See 42 U.S.C.A. § 1395f(a)(7) (West Supp. 2004) (stating that a hospice physician and the patient's attending physician must certify a patient as "terminally ill" "in the first 90 day period" and that a hospice physician must certify the patient as terminally ill "in a subsequent 90- or 60-day period ..."). When initially enacted, the Medicare Hospice Benefit included a 210 day limit. This included two 90 day periods and a third 30 day period. However, Congress repealed the limit effective for services furnished on or after January 1, 1990 in the Medicare Catastrophic Coverage Repeal Act of 1989. See OIG, Hospice PATIENTS, infra note 71, at I (stating that "[t]he repeal of the 210 day limit shifted the financial risk for patients living longer than 210 days from the hospice to Medicare ... Before the repeal of the 210 day limit for hospice care, hospices would have to provide uncompensated care for patients who lived beyond 210 days and continued to require hospice care.") $I d$. at 11.

${ }^{12}$ See 42 U.S.C.A. § 1395d(d)(1) (West Supp. 2004) (stating that payment for hospice care may be made "with respect to an individual only during two periods of 90 days each and an unlimited number of subsequent periods of 60 days each ...").

${ }^{13}$ See 42 U.S.C.A. $\S 1395 \mathrm{~d}(\mathrm{~d})(2)($ A) (West Supp. 2004).

${ }^{14}$ See Medicare Program; Hospice Care Amendments, 67 Fed. Reg. 70,363, 70,364 (Nov. 22, 2002).
} 
The MHB must be delivered by an interdisciplinary team including a physician, registered nurse, social worker, and pastoral or other counselor. ${ }^{15}$ This team, with the patient, the patient's family and the patient's primary or attending physician

assesses, coordinates, and provides the appropriate palliative and supportive care to hospice patients and their families. Additionally, the ... team helps establish the patient's plan of care, providing or supervising hospice care and services, and periodically reviewing and updating the care plan. The team also manages the patient's discomfort and symptom relief. ${ }^{16}$

Volunteers are also used to provide home visits. ${ }^{17}$ The hospice physician and nurse are on call 24 hours a day, seven days a week to provide consultation by phone or in person, if necessary. ${ }^{18}$ In addition to providing these services to dying patients, hospice also provides bereavement services to a patient's family members after the patient has died. ${ }^{19}$

Under the MHB there are four levels of care and corresponding per diem payment rates: (1) routine home care which is care delivered in the patient's home; (2) continuous home care, i.e., care delivered at a patient's home requiring a minimum of eight hours of care per day (half of which must be actual nursing care), (3) inpatient respite care or care for which the hospice must make the financial arrangements for the hospitalization of a hospice patient in either a hospital, hospice inpatient facility, or a skilled nursing facility (SNF) when necessary to relieve the caregivers at home, and (4) general inpatient care, provided in either a hospital, hospice inpatient facility, or a SNF for pain control or acute or chronic symptom management which

\footnotetext{
${ }_{16}^{15}$ See 42 C.F.R. § 418.68(a) (2003); 42 U.S.C.A. § 1395x(dd)(2)(B) (West Supp. 2004).

${ }^{16}$ GAGE ET AL., supra note 1, at 5-6.

${ }^{17}$ See 42 C.F.R. $\S 418.70$ (2003); 42 U.S.C.A. $§ 1395 x(d d)(2)(E)$ (West Supp. 2004). The initial hospice legislation required hospices to use volunteers and mandated "records on their use, cost savings, and the expansion of care and services achieved by doing so." GAGE ET AL., supra note 1, at 6.

${ }^{18}$ See 42 C.F.R. $\S 418.50$ (2003). The MHB includes a number of benefits not available under other Medicare programs such as "non-IV therapy outpatient prescription drugs for pain relief and symptom management, homemaker services, and bereavement counseling for both the patient and their family members." GAGE ET AL., supra note 1 , at 8 .

${ }^{19}$ See 42 C.F.R. $\S 418.88$ (2003).
} 
cannot be managed in another setting. The FY 2004 reimbursement rates for these levels of care ranged from $\$ 118$ for routine home care to $\$ 689$ for continuous home care. ${ }^{20}$

While Congress established the Medicare Hospice Benefit (MHB) in $1982,{ }^{21}$ it was not until 1986 that the MHB was made available to nursing home residents. ${ }^{22}$ Most nursing home residents eligible for hospice are over sixty-five and thereby qualify for the $\mathrm{MHB} .^{23}$ For purposes of the MHB, the nursing home is considered the patient's home and the majority of care provided in the nursing home is level one, routine home care.

When a nursing home resident elects the MHB, the hospice takes on responsibility for the professional management of the patient's care for his or her terminal condition. Certain core services, including nursing care, physician services, medical social services, and counseling must be provided directly by the designated hospice provider. ${ }^{24}$ Other services, including physical therapy, occupational therapy, speech-language pathology services, home health aide and homemaker services, and medical supplies (including drugs and biologicals for palliation and management of the terminal illness) must be provided either directly by hospice employees or by arrangement with other providers. ${ }^{25}$ For these services, the Medicare program pays the hospice provider based on the routine home care rate unless the beneficiary qualifies for a higher level of care.

The nursing home continues to provide the patient's room and board and other services unrelated to care of the patient's terminal illness. In addition to lodging and food, for residents

\footnotetext{
${ }^{20}$ See Centers for Medicare \& Medicaid Services, DHHS, Program Memorandum: Medicare Program-Update to the Hospice Payment Rates, Hospice Cap, Hospice Wage Index and the Hospice Pricer for FY 2004 (CMS Pub. 60A, Transmittal A-03-057), at http://www.cms.hhs.gov/manuals/pm_trans/a03057.pdf (July 3, 2003).

${ }^{21}$ See Tax Equity and Fiscal Responsibility Act (TEFRA) of $1982 \S 122$, Pub. L. No. 97-248, 96 Stat. 324, 356-63 (codified as amended in scattered sections of 26 and 42 U.S.C.).

${ }^{22}$ See Omnibus Budget Reconciliation Act of 1986, Pub. L. No. 99-509, 100 Stat. 1874.

${ }^{23}$ Those who are not Medicare eligible may have private insurance that covers hospice care or may be eligible for the Medicaid hospice benefit. The majority of state Medicaid programs cover hospice services. Medicaid requires that, if a state does provide hospice services, state programs include "at minimum" the same services covered by Medicare. See GAGE ET AL., supra note 1, at 13.

${ }^{24}$ See 42 C.F.R. $\$ \S 418.80$ - 418.88 (2003) (outlining core services that must be provided by the hospice).

${ }^{25}$ See 42 C.F.R. $\S 418.56$ (2003) (specifying terms for services provided by arrangement with other entities) and $\S \S$
} 
who are dually eligible for Medicare and Medicaid, room and board includes "performance of personal care services, assistance in activities of daily living, socializing activities, administration of medication, maintaining the cleanliness of a resident's room and supervising and assisting in the use of durable medical equipment and prescribed therapies.",26

\section{Benefits of Hospice for NH Patients}

Nursing home residents in hospice, as compared to those who do not receive hospice services, may receive better pain control, "better relief of dyspnea, fewer uncomfortable symptoms of dying, better attention to hygiene, better total comfort, and better bereavement support."27 A study commissioned by DHHS, made publicly available in March 2000, compared two cohorts of nursing home patients at the end-of-life-hospice and non-hospice. The data were from 1992 - 1997 and included 2,655 hospice patients and 7,929 non-hospice patients matched on time interval between last Minimum Data Set and death, diagnostic group, and state of nursing home residence. The researchers concluded that nursing home patients enrolled in hospice, when compared to those at the end-of-life who were not in hospice:

- were significantly less likely to be hospitalized in their last six months of life,

- received superior pain assessment since pain was more likely to be detected,

- if in pain, were more likely to be treated with pain medication, and

- were less likely to be physically restrained or have feeding tubes. ${ }^{28}$

The study further found that hospice staff served an important educational function in the nursing

\footnotetext{
$418.90-.100$.

${ }^{26}$ Centers for Medicare \& Medicaid Services, Hospice Manual, Pub. 21, ReV. $55 \S 204.2$, at http://www.cms.hhs.gov/manuals/21_hospice/hs200.asp (Last modified on July 30, 2003).

27 Timothy J. Keay \& Ronald S. Schonwetter, The Case for Hospice Care in Long Term Care Environments, 16 Clinics IN GERIATRIC MED. 211 (2000).

${ }^{28}$ See Susan C. Miller ET Al., DHHS, Outcomes AND Utilization FOR Hospice AND Non-HospiCE NuRsing FACILITY DECEDENTS, at http://www.aspe.hhs.gov/daltcp/reports.shtml (Mar. 2000). The study used the Minimum Data Set (MDS) and Medicare enrollment and claims data for the states of Kansas, Maine, Mississippi, New York and South Dakota.
} 
home and often had a "beneficial spillover" effect, improving the care of non-hospice, terminally ill patients in the facility. ${ }^{29}$

\section{BARRIERS TO HOSPICE UTILIZATION IN LONG TERM CARE Attitudes, Culture and Awareness}

There is a significant body of literature alleging that failure of nursing homes to utilize hospice can be attributed to lack of knowledge of and attitudes toward the benefit on the part of patients, families, and nursing home staff and administrators, as well as cultural differences between the two providers. As regards attitudes of nursing home administrators, one study of 23 nursing homes in the same state found that rates of hospice use varied by facility from $2 \%$ to $39 \% .{ }^{30}$ Upon further research, the authors concluded that the most significant factor accounting for the differences seemed to be whether or not the nursing home administrator was sympathetic to hospice care. Administrators who were not sympathetic to hospice had the following views in common:

(1) nursing homes were doing a good job with terminal patients before hospice was available and therefore hospice was not really needed;

(2) hospice had been imposed without appreciation for the procedural problems and costs involved;

(3) hospice practices might get too close to euthanasia;

(4) uncertainty about the financial implications of assigning a Medicare patient to hospice. $^{31}$

Others have described the institutionalized culture of the nursing home as in sharp contrast to the individualistic approach of hospice:

\footnotetext{
${ }^{29} I d$.

${ }^{30}$ See Bent Jones et al., Differential Utilization of Hospice Services in Nursing Homes, 12 HosPICE J. 41 (1997).

${ }^{31}$ See id.
} 
Hierarchical staffing structures with high turnover and staff burnout are typical of the nursing home, while hospice agencies promote a democratic system which includes family and volunteers. The nursing home generally focuses on custodial care and assisting in the activities of daily living, while hospice emphasizes psychosocial and spiritual needs. With hospice care, pain control is concerned with preventing pain through regular liberal dosages [of pain medication] rather than responding with minimal dosages after pain has already occurred. In hospice services, open communication about death and bereavement is encouraged and supported, while the nursing home environment provides little if any training or discussion about death and grief. ${ }^{32}$

\section{Government Policies and Practices}

While attitudes, knowledge and culture are part of the problem, there are also numerous assertions in the literature that other factors are at work, including government practices and policies to deter utilization of hospice services in the long term care setting. These have included: (1) Medicare nursing home regulations that focus on rehabilitation and restoration in contrast to palliation; (2) the six month life expectancy eligibility criteria for the MHB; (3) reimbursement schemes for hospice and nursing homes that encourage skilled nursing care over the MHB; and (4) scrutiny by the OIG of hospice referrals to nursing homes and contractual relationships between these two providers. These government policies and actions arguably reinforce the cultural and attitudinal barriers to use of hospice.

\section{$\underline{\text { Regulations }}$}

The Medicare statute explicitly states that a nursing home must provide services "to attain or maintain the highest practicable physical, mental and psycho-social well-being of each resident. .."33 Several commentators have alleged that this approach to care, which encourages "aggressive rehabilitation, medical treatment and maintenance of functional capacity"34 may conflict with the needs of dying patients and result in "unsatisfactory care at the end-of-life with

\footnotetext{
${ }^{32}$ Id. at 45, citing Anne Munley et al., Humanizing Nursing Home Environments: The Relevance of Hospice Principles, 15 InT'L J. AgING \& Hum. Dev. 263 (1982).

3342 U.S.C.S. $\$ \S 1395 \mathrm{i}-3$ (a)-(h) and 1396r (a)-(h) (2003).

${ }^{34}$ National Hospice Organization, Nursing Home TASK ForCe RePORT (hereinafter NHO RePORT) 6 (1998).
} 
pain and other distressing symptoms inadequately managed, and failure to address spiritual and emotional needs." 35

Johnson observes that the nursing home regulations implementing the statutory requirements "impose standards that assume that physical, mental, and emotional decline may be indicators of deficiencies in care of elderly residents. ${ }^{, 36}$ Furthermore, the regulations mandate the "use of a comprehensive, uniform assessment system"37 -- the Resident Assessment Instrument-- which explicitly culls out for further investigation any evidence of resident decline. As a result, physical, mental and emotional changes that often accompany the normal dying process may be identified as deficiencies. ${ }^{38}$ An example often mentioned by hospice staff is a patient's unwillingness to eat. Hospice staff view this as a natural part of the dying process but they find that nursing home staff are often concerned with the possibility of "being cited for substandard care if a resident is malnourished or dehydrated." $" 39$ This results in feeding tube use for many dying residents "despite the lack of evidence demonstrating any health benefits from this intervention." 40

Kapp has asserted that nursing home administrators' and providers' sensitivity to legal risk makes them much more likely to err on the side of maintenance and restoration of function than comfort care in the context of dying patients. ${ }^{41}$ They do not wish to attract the attention of surveyors who might perceive weight loss or inadequate nutrition of a patient as an indication of inadequate care.

\footnotetext{
${ }^{35}$ Parker-Oliver, supra note 5 at 147, citing Timothy J. Keay, Palliative Care in the Nursing Home, 23 GENERATIONS 96 (1999).

${ }^{36}$ Sandra H. Johnson (forthcoming, manuscript on file with the authors)

${ }^{37}$ Marshall B. Kapp, Legal Anxieties and End-of-Life Care in Nursing Homes, 19 IssuES IN LAW \& MED. 111,128 (2003).

${ }^{38}$ See Johnson, supra note 36; see also Zerzan, et al., supra note 3.

${ }^{39}$ GAGE ET AL., supra note 1 at 60.

${ }^{40}$ Susan C. Miller and Vincent Mor, The Opportunity for Collaborative Care Provision: The Presence of Nursing Home/Hospice Collaborations in the U.S. States, 28 J. PAIN \& SYMptom MgT. 537 (2004).

${ }^{41}$ See Kapp, supra note 37.
} 
In one study, nursing facility staff and hospice professionals stated that the nursing home “orientation" makes it difficult for "nursing facility staff to switch between providing restorative rehabilitative care and palliative care." ${ }^{42}$ This difference in focus also affects the administration of narcotics, which hospice staff view as a necessary tool for pain management and may prescribe in large doses and/or on a fixed schedule. Nursing home staff fear, however, that this may be seen as "overmedication" by nursing home surveyors or as a violation of nursing home regulations that prohibit the use of chemical restraints. ${ }^{43}$

Hospice regulations may also contribute to the infrequent referral of nursing home patients to hospice. Here, the obstacle has been the requirement that physicians certify a patient as having an estimated life expectancy of six months or less. While this concern is not unique to patients residing in nursing homes, the requirement has historically favored referral of cancer patients whose disease trajectory is relatively predictable, and disfavored those for whom the trajectory of their illness and death is relatively unpredictable-e.g., individuals with congestive heart failure or Alzheimer's disease. Nursing home residents are more likely to be in this latter group.

\section{Reimbursement Issues}

The reimbursement systems under Medicare for hospice and nursing homes, in particular the SNB, may also add to the host of disincentives for hospice use by long term care facilities. The per diem payment scheme for each arguably reinforces structural anachronisms in the Medicare program that require individuals to choose between curative and palliative care and that encourage rehabilitation over palliation. Moreover, for residents who are eligible for both

\footnotetext{
${ }^{42}$ GAGE ET AL., supra note 1, at 59.

43 "Chemical Restraints" is defined by the regulations as "any drug that is used for discipline or convenience and not required for treatment of medical symptoms." 42 C.F.R. $\S 483.13$ (a).
} 
Medicare and Medicaid, the per diem reimbursement for the MHB and Medicaid room and board

has created confusion over which provider is responsible for some services.

In order to be eligible for the SNB, a patient must have been discharged to the nursing home from a hospital with a minimum three day stay and must need skilled nursing care. The benefit is available for up to100 days of skilled care and covers medical care as well as the resident's room and board. ${ }^{44}$ In general, a nursing home resident who is eligible for both the SNB and the MHB must choose one or the other. ${ }^{45}$ When a resident qualifies for the SNB for treatment of a terminal illness, even if he or she is also eligible for, and may prefer, hospice care, the resident and her family may be reluctant to elect the MHB as, in contrast to the situation under the SNB, the MHB does not cover room and board. Thus, unless the resident is also Medicaid eligible or has other health insurance that would cover the room and board cost, the resident would be saddled with paying this cost out of pocket. ${ }^{46}$ These residents may forgo the hospice services they want and need due to the financial incentive to elect the SNB.

Residents who are Medicaid eligible would theoretically be financially indifferent to the SNB and the MHB as both their medical care and room and board would be covered by a third party payer. The nursing facility, however, may not be indifferent between the two benefits but, in many cases, may prefer that the resident receive the SNB as it would be financially

\footnotetext{
${ }^{44}$ Medicare covers $100 \%$ of the first 20 days of skilled care. For days $21-100$, patients are required to pay a coinsurance amount equal to one eighth of the Medicare inpatient hospital deductible. See 42 U.S.C.A. § 1395 e(a)(3) (West 2003). For FY 2004 this was approximately $\$ 110$.

${ }^{45}$ Under certain limited circumstances, a nursing home resident may be eligible for both the Medicare Skilled Nursing Benefit (SNB) and the MHB. The resident may receive both at the same time if the SNB involves care for a non-terminal condition, e.g., a patient with breast cancer may receive speech therapy after a stroke. However, if the care is exclusively for treatment of a terminal condition, the resident may only receive one benefit at a time. For example, if the patient is terminally ill with congestive heart failure (CHF) and is returning to the nursing home after a hospital visit for treatment of an acute episode s/he may be eligible for both the SNB and the MHB for care related to the CHF. However, the patient may choose only one of these benefits for treatment of this condition. In some cases, there is not a bright line indicating whether or not treatment under the SNB is related to a terminal condition. For example, a cancer patient may experience a series of bone fractures. These may or may not be related to brittleness caused by the cancer or cancer therapy.

${ }^{46}$ In 2002 , the average nationwide private pay per diem rate was $\$ 142.56$ for a semiprivate room and $\$ 167.82$ for a private room. See Mature Market Inst., MetLife, InC., MetLife Market Survey On Nursing Home And HOME CARE COSTS 6, at http://www.metlife.com/WPSAssets/83700920001018640690V1FNH\%20HC\%20Survey\%202002.pdf (Apr. 2002).
} 
advantageous to the facility. If a resident receives the SNB, the facility will receive a per diem rate based on the skilled nursing facility (SNF) prospective payment reimbursement system. Under this system, the specific rate will depend on the particular RUGs (resource utilization group) category of the patient. Per diem reimbursement for all RUGs categories in 2004 was at least $\$ 140$ per day, for most it was over $\$ 200$, and for some it was more than $\$ 400 .^{47}$ Nursing facilities would compare this payment to the per diem they would receive for room and board from Medicaid when the patient receives the MHB. If a patient is dually eligible for Medicare and Medicaid, the hospice is reimbursed for its medical services by Medicare and is reimbursed for the nursing home room and board charges by Medicaid at a rate equal to at least $95 \%$ of the established room and board rate for nursing homes. The hospice then, pursuant to a contract, reimburses the nursing home in amounts between $95 \%$ and $100 \%$ of the Medicaid room and board rate for providing the nursing home services. ${ }^{48}$ In 2002 , the average per diem nursing home rate was $\$ 265$ for Medicare residents ${ }^{49}$ and $\$ 118$ for Medicaid residents. ${ }^{50}$

The possibility that nursing homes may be steering patients to the Medicare SNB when residents qualify for, and may be more appropriately placed in, hospice because the SNB pays more than the Medicaid room and board per diem is troubling. While the issue of "steering" would be difficult to assess due to mixed motives of both patients and nursing facilities, there is clearly a financial incentive for nursing facilities to engage in such behavior.

While this financial incentive has been mentioned in the literature as an obstacle to hospice use by many nursing homes, it is not clear how many nursing home residents are

\footnotetext{
${ }^{47}$ See Medicare Program; Prospective Payment System and Consolidated Billing for Skilled Nursing FacilitiesUpdate - Notice, 69 Fed. Reg. 45,775 - 45,822 (July 30, 2004).

${ }^{48}$ The Omnibus Budget Reconciliation Act of 1989 provided that the hospice payment to nursing facilities "take into account the room and board furnished by the facility, equal to at least 95 percent of the rate that would have been paid by the State under the plan for facility services in that facility for that individual." Codified at 42 U.S.C.A. $\S 1396 a(a)(13)(B)$ (West Supp. 2004).

${ }^{49}$ CMS, "Medicare Skilled Nursing Facility (Non-Swing Bed) Utilization and Expenditure Calendar year 2002." (The figure does not include beds that "swing" between hospital and SNF levels of care.)

${ }^{50}$ David C. Grabowski, et al., Project HOPE; "Recent Trends in State Nursing Home Payment Policies," Health Affairs Web Exclusive, June 16, 2004 at http://content.healthaffairs.org/cgi/content/full/hlthaff.w4.363/DC1.
} 
simultaneously eligible for the Medicare skilled benefit, the MHB, and Medicaid. However, a March 2000 report prepared for DHHS, based on 9,299 nursing home residents who had at least one hospice episode, found that $73 \%$ had received care under the SNB at some point prior to hospice admission. The time between SNF discharge, i.e., termination of the SNB, and hospice admission varied significantly but $26 \%$ were admitted to hospice within 0 to 1 day after SNF discharge. ${ }^{51}$ The study authors state that the data "suggests that hospice care may have been appropriate earlier if it were available to patients in SNF beds.",52

A second reimbursement issue that may deter hospice and nursing homes from collaborating is confusion created by the overlap in services covered by the per diem hospice benefit and the per diem nursing home payment for room and board. For "dual eligibles," i.e. individuals who are eligible both for Medicaid and the Medicare hospice benefit, it is not clear which entity is responsible for some services because the per diem of each covers those services. Examples include "personal health services" and drugs used in connection with a terminal illness. The MHB covers services necessary for the palliation or management of terminal illness. ${ }^{53}$ Included in these services are home health aide services which encompass "personal care services." ${ }^{, 54}$ The nursing home Medicaid per diem for room and board also includes personal care services. ${ }^{55}$ Based on concerns expressed by the OIG that hospices were providing fewer services to residents in the nursing home than in the community, some hospice providers have asked whether they should be providing the same services to nursing facility residents that they provide to patients in the community even if it means duplicating services provided by the nursing home staff.

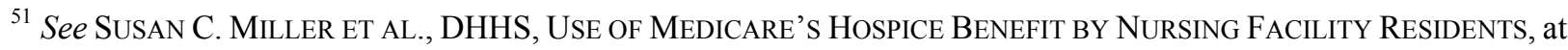
Skilled Nursing Facility Care and Hospice Admission (Mar. 2000), available at http://www.aspe.hhs.gov/daltcp/reports/nufares.htm.

${ }^{52} \mathrm{Id}$.

${ }^{53}$ See 42 CFR $\S 418.200$.

${ }^{54}$ See 42 CFR $§ 418.204(\mathrm{~g})$.
} 
In May 2002, CMS issued a guidance memorandum to State Medicaid Directors

regarding the responsibility of each provider for the implementation of the MHB for nursing home residents. ${ }^{56}$ The memorandum was subsequently incorporated into the Medicaid State Operations Manual. ${ }^{57}$ This guidance affirms that hospice services must be provided "at the same level" to nursing home residents as to patients residing in their home, however it is not explicit as to how comparability is to be determined.

A similar issue is created by payment for drugs used by "dually eligibles" in connection with their terminal illness. The MHB covers drugs used for palliation and management of a patient's terminal illness and related conditions. ${ }^{58}$ In addition, the Medicaid per diem payment in some states may include the provision of such drugs. Under these circumstances, one hospice provider asked for an OIG Advisory Opinion as to whether a hospice can pay a nursing home above the Medicaid per diem rate for drugs in connection with a patient's terminal illness. The OIG responded that in the circumstances presented the arrangement could "involve prohibited remuneration under the anti-kickback statute" but that there was insufficient information provided by the hospice to determine whether there was an actual violation. ${ }^{59}$ Uncertainty regarding potential legal risk created by these unclear payment rules may also deter nursing homes from utilizing hospice services.

\section{Enforcement of Fraud and Abuse Rules}

The fraud and abuse concerns for nursing homes referring patients to hospice arise at two

\footnotetext{
${ }^{55}$ See Medicare Hospice Manual Centers for Medicare \& MedicAid SERviCes, Hospice Manual, Pub. 21 , ReV. Sec. 204.2 at http://www.cms.hhs.gov/manuals/21 hospice/hs200asp .

${ }^{56}$ See Memorandum from Steven A. Pelovitz, Director, Survey and Certification Group, Center for Medicaid and State Operations to Associate Regional Administrator, DMSO, and State Survey Agency Directors, Promising Practices for Implementing the Medicare Hospice Benefit for Nursing Home (NH) Residents, (Ref: S\&C-02-29), available at http://www.cms.hhs.gov/medicaid/survey-cert/sc0229.pdf (May 10, 2002).

${ }^{57}$ See Centers for Medicare \& Medicaid Services, Publication 100-7, State Operations Manual $\S 2082$, available at http://www.cms.hhs.gov/manuals/107_som/som107c02.pdf (last modified June 18, 2004).

${ }^{58}$ See 42 C.F.R. $\S 418.96$.

${ }^{59}$ OIG Advisory Opinion No. 01-20 (2001) at http://www.oig.hhs.gov/fraud/docs/advisoryopinions/2001/ao00_3.htm
} 
levels. The first is whether the nursing home enters into a formal contractual agreement with a hospice or hospices to refer their terminally ill patients for hospice care. This is significant as "facilities that do not contract with a participating hospice may not make the benefit available to their residents. $" 60$ The second is whether, on a case-by-case basis, the nursing home will refer a specific nursing home resident to a hospice program.

As regards the latter, some have attributed hesitancy on the part of health care providers to refer a patient to hospice when they are not extremely certain of the patient's life expectancy because they fear it would violate fraud and abuse laws. Such fear has not been without merit. In 1995, the OIG, under the name Operation Restore Trust, began a series of investigations of fraud and abuse in home health agencies, nursing homes, durable medical equipment companies and hospice organizations. The inclusion of hospice came after audits of two Puerto Rican hospices found that 77 percent of one hospice's patients were ineligible because they were not terminally ill and after an audit report of a Florida hospice, released in 1996, claimed that the hospice erred in admitting 176 patients out of 364 patients who were either enrolled for more than 210 days or had been discharged alive over a 27-month period. This prompted the OIG to look more closely at the practices of other hospices and in April 1998, the OIG issued a report on Medicare Hospice Beneficiaries. ${ }^{61}$ The report, based on inspections of 36 hospice agencies, found that a significant portion of hospice patients in nursing homes were not eligible for the MHB because they were not considered to be "terminally ill." The results of the report were controversial and disputed by the hospice industry. In its comments on a draft of the OIG report, the National Hospice Organization (NHO) stated that it "continues to be distressed by the OIG's characterization of patients being ineligible for the Medicare hospice benefit where differences in medical opinion related to the prognosis of a patient exist between OIG reviewers and the

\footnotetext{
${ }^{60}$ GAGE ET AL., supra note 1 , at 2.

${ }^{61}$ See OfFICE OF Inspector Gen., DHHS, MedicARe Hospice BenEFICIARIES: Services AND ELIGIBILITy (OEI-04-
} 
patient's attending physician and hospice medical director. The well-regarded Institute of Medicine has very clearly warned the OIG not to draw conclusions about the veracity of hospice programs based on these differences of medical opinion." ${ }^{2}$

An article in The Wall Street Journal, published in June 2000, provides some indication of the scrutiny the OIG has applied to hospices and hospice patients and would appear to support an argument that the OIG's actions may have had a chilling effect on referrals to hospiceespecially for patients for whom the disease trajectory is difficult to predict. ${ }^{63}$ According to the article, in February 1997, five hospice patients and a hospice provider received a letter warning that the Medicare beneficiaries might each owe Medicare tens of thousands of dollars. The beneficiaries were mostly in their $80 \mathrm{~s}$ and $90 \mathrm{~s}$, had been diagnosed as terminally ill, had been treated by a local hospice and, most significantly, their life spans had exceeded the six month guideline for determination of terminal illness. The total amount that the five patients were expected to pay back was $\$ 450,000$. The letters told the recipients: "You are not eligible for the Medicare hospice coverage" and added that "Medicare will recoup the money that it inappropriately paid." The hospice challenged Medicare's decision to recoup the funds and a hearing on the case was held in September 1998. The administrative law judge held for the hospice provider and beneficiaries, stating that there was good reason to believe that the patients were terminal when they were admitted and that the fact that some patients, "exceeded those expectations does not indicate that a fraud was perpetrated." The government appealed the decision and lost.

93-00270, Apr. 1998), available at http://oig.hhs.gov/oei/reports/oei-04-93-00270.pdf.

${ }^{62}$ Letter from John J. Mahoney, President, National Hospice Organization to the Hon. June Gibbs Brown, Inspector General, DHHS (Jan. 29, 1998).

${ }^{63}$ See Lucette Lagnado, Rules Are Rules: Hospice's Patients Beat the Odds, So Medicare Decides to Crack Down, WALL St. J., June 5, 2000, at A1. 
In order to protect beneficiaries from similar future government actions, as part of the

1997 Balanced Budget Act, Congress extended limitation on liability protection ${ }^{64}$ to a

beneficiary enrolled in a hospice "where there is a denial of claims due to a determination that

the individual is not terminally ill." ${ }^{, 65}$ Also, in 2000, Congress clarified the requirement for

certification of terminal illness to make it clear that physicians could make this decision based on

the physician's clinical judgment regarding the normal course of the individual's illness. ${ }^{66}$ This

statutory change, although consistent with prior DHHS policy, ${ }^{67}$ was made to make it clear to

physicians that they could base their judgment on the typical course of a given illness rather than

on whether a specific individual would live more than six months. ${ }^{68}$

While these changes may have made hospice physicians and nursing homes more

comfortable with referring patients to hospice, the practice of Medicare fiscal intermediaries

(FIs) of scrutinizing cases in which patients live longer than 6 months may have reinforced

concerns about referrals to hospice of patients with diagnoses for which it is difficult to predict

life expectancy. ${ }^{69}$ In such cases, the FIs may withhold reimbursement until satisfied that the

beneficiary meets the FI's criteria for terminal illness.

\footnotetext{
${ }^{64}$ Section 1879 of the Act "provides protections from liability for charges for certain denied claims to beneficiaries who, acting in good faith, receive inpatient or outpatient services from Medicare Part A providers, or items or services from Medicare Part B suppliers which accept assignment.” Health Care Financing Administration, DHHS, Program Memorandum: Hospice Provisions Enacted by the Balanced Budget Act (BBA) of 1997, at 3 (HCFA Pub. 60A, Transmittal A-98-27), at http://www.cms.hhs.gov/medicaid/hospice/a9827.pdf (Sept. 1998).

${ }^{65} \mathrm{Id}$.

${ }^{66}$ See Medicare, Medicaid, and SCHIP Benefits Improvement and Protection Act of 2000, Pub. L. No. 106-554, 114 Stat. 2763, § 322 (codified in 42 U.S.C. 1395f(a)). In addition, the amendment requires the Secretary of DHHS to "conduct a study to examine the appropriateness of the certification regarding terminal illness .... In conducting such study, the Secretary shall take into account the effect of [the certification] amendment." Id.

${ }^{67}$ See Medicare Program; Hospice Care Amendments, 67 FeD. REG. 70,363 - 70,364 (Nov. 23, 2002).

${ }^{68}$ In addition, perhaps in response to this kind of press, in Sept., 2000, the outgoing head of the Health Care Financing Administration (HCFA) (now the Centers for Medicare and Medicaid Services (CMS)), sent a letter to 2,200 hospices saying she wanted to counter a "disturbing misperception" among those who care for the dying that patients who outlive the narrow reimbursement timeline set by Congress risk losing their coverage and being hit with severe financial penalties. In the letter, she proposed a pilot program in which hospices could obtain preauthorization from Medicare contractors for hospice care "in cases where the prognosis is difficult." Letter from Nancy-Ann DeParle, Administrator, Health Care Financing Administration, to Medicare Hospices (Sept. 12, 2000), available at $\mathrm{http}: / /$ aging.senate.gov/events/hr59ltr.htm.

${ }^{69}$ See letter to Fred McDaniel, Hospice Care, Inc. from John W. Olds, RHHI Medical Director, Cahaba GBA (Dec. 10,2004 ) (stating that neither letters from CMS administrators, "nor CMS regulation, nor social security law establish that the physician's certification is the final arbiter of hospice eligibility" and that "determination of a 6
} 
The fraud and abuse concerns related to contractual arrangements have received less discussion in the literature than those regarding individual referrals and whether a patient meets the hospice eligibility requirement that a patient have an estimated life expectancy of six months or less. $^{70}$ Yet, a 1998 OIG fraud alert regarding contracts between nursing homes and hospice may have also affected referrals of nursing home residents to hospice. The alert was prompted by a substantial increase in Medicare payments for hospice services, including those provided to beneficiaries residing in nursing facilities, and by the results of two studies published in 1997 by the Office of the Inspector General (OIG). ${ }^{71}$

In its 1998 fraud alert, the OIG asserts that arrangements between nursing homes and hospices are vulnerable to fraud and abuse because nursing home staff often decide whether to bring hospice services into their facility for a terminally ill resident. ${ }^{72}$ The OIG believes patients residing in nursing homes may be particularly desirable from a hospice's financial standpoint because they represent a sizeable pool of potential hospice patients with (according to the OIG)

month life expectancy for a beneficiary who has been in hospice for many certification periods is more likely accurately made by reviewing that patient's trend toward decline, stability, or improvement and not by the LCD criteria." See also LCD for Hospice - Determining Terminal Status for the Cataba fiscal intermediary at http://www.iamedicare.com/Provider/policy/L13653.htm.

${ }^{70}$ A March 2000 report prepared for DHHS by the Urban Institute stated: “According to anecdotal reports, access to hospice care in the nursing facility may have become more difficult since the ... OIG . . . questioned the hospice lengths of stay and eligibility of beneficiaries residing in nursing facilities." GAGE ET AL., supra note 1 at 1-2. ${ }^{71}$ See OfFice Of INSPECTOR GENERAL, DHHS, HOSPICE PATIENTS IN NURSING HOMEs 6-8 (OEI-05-95-00250), at http://oig.hhs.gov/oei/reports/oei-05-95-00250.pdf (Sept. 1997) [hereinafter OIG, HOSPICE PATIENTS] (finding that nursing home hospice patients in a sample of 22 hospices received fewer nursing and aide services from hospice staff than hospice patients living at home and that many of these services were also provided by the nursing home staff when hospice staff were not present). An initial draft of this report recommended that the Medicare hospice benefit be eliminated for patients living in nursing homes. See id. at ii. See also OfFICE OF InSPECTOR GenERAL, DHHS, HosPiCE AND NURSING HOME CONTRACTUAL RELATIONSHIPS 4 (OEI-05-95-00251), at http://oig.hhs.gov/oei/reports/oei-05-95-00251.pdf (Nov. 1997) (finding that almost all hospices reviewed paid "nursing homes the same or more than what Medicaid would have paid for nursing home care if the patient had not elected hospice."); OfFICE OF InSPECtOR Gen., DHHS, ENHANCED CONTROLS NEEDED TO ASSURE VALIDITY OF MedicARE HosPiCE ENROLLMENTS (A-05-96-00023), at http://oig.hhs.gov/oas/reports/region5/59600023.pdf (Nov. $4,1997)$. The latter finding was based on 17 contracts between hospice organizations and nursing homes. The OIG found that 10 of 17 hospices paid the nursing home $100 \%$ of the Medicaid per diem, five paid $105 \%$, one paid $120 \%$ and one paid less than $100 \%$. See GAGE ET AL., supra note 1, at 20. While these reports indicated some problems with the nursing home-hospice relationship, some commentators criticized the conclusions based on the very small sample size used in the studies, asserting that they were not adequate to allow generalization of results. See Memorandum from David F. Garrison, Principal Deputy Assistant Secretary for Planning and Evaluation, HCFA, to June Gibbs, Inspector General (July 22, 1997) (reprinted in OIG, HOSPICE PATIENTS, supra); see also infra text accompanying note 88 . 
longer average lengths of stay than non-institutionalized patients thus potentially generating higher gross revenues than home care patients in the community. Furthermore, the possible overlap in the services provided by the hospice and nursing home is an opportunity for either provider to reduce services and costs. Based on the per diem payment system for hospice services, such reduction in services could result in higher profits. ${ }^{73}$

According to the OIG, these opportunities may result in illegal inducements to influence the selection of a hospice in nursing homes whose operators may select the providers with whom they will contract and restrict residents to one or two providers. The OIG identified several benefits offered by hospices to nursing homes as potential kickbacks designed to influence the referral of patients, including:

- "room and board" payments to the nursing home in amounts in excess of what the nursing home would have received directly from Medicaid had the patient not been enrolled in hospice, i.e., greater than 100 percent of the facility's Medicaid rate;

- $\quad$ payments to the nursing home for "additional" services that Medicaid considers to be included in its room and board payment to the hospice;

- referring hospice patients to a nursing home to induce the nursing home to refer its patients to the hospice;

- providing free (or below fair market value) hospice care ("bridge services”) to nursing home patients for whom the nursing home is receiving Medicare payment under the skilled nursing facility benefit, with the expectation that after the patient exhausts the skilled nursing facility benefit, the patient will receive hospice services from that hospice;

\footnotetext{
${ }^{72}$ See Publication of OIG Special Fraud Alerts: Fraud and Abuse in Nursing Home Arrangements With Hospices, 63 Fed. Reg. 20,415, 20,416 (April 24, 1998) [hereinafter OIG Special Fraud Alert].

${ }^{73}$ See id.
} 
- providing staff at its expense to the nursing home to perform duties that otherwise would be performed by the nursing home. ${ }^{74}$

Violation of the anti-kickback statute carries with it the possibility of criminal prosecution, civil monetary penalties, and may also lead to exclusion from federal health care programs. ${ }^{75}$

A subsequent OIG Advisory Opinion tempered the impact of the 1998 Fraud Alert by concluding that the OIG would not subject a hospice to sanctions where the hospice was providing services, at below market value, to nursing home patients not enrolled in hospice when the services were being provided by unpaid volunteers, were supporting a vulnerable population, and resulted in benefits that would be considered primarily "intangible and psychic." Opinion was encouraging to the hospice industry, a subsequent Opinion, discussed above, may have added to the confusion created by the possibility of overlapping services (the provision of drugs) covered under both the MHB and the Medicaid "room and board" per diem. ${ }^{77}$

\section{Empirical Data on Chilling Effect}

While there are no definitive data on the impact of these practices and policies on nursing home referrals to hospice, a study conducted in 2001 and 2002 in the state of Maryland sought to better understand the effect of financial and fraud and abuse concerns on nursing home/hospice contractual relationships. Researchers interviewed representatives from $89 \%$ of hospices and $43 \%$ of nursing homes in the state. The majority of hospice respondents were aware of the Office of Inspector General's Special Fraud Alert regarding the relationships between hospices and nursing homes. Of those, half thought the fraud alert had made a difference in the way they provided services. Several hospice respondents clearly articulated their belief that the rules are an

\footnotetext{
${ }^{74}$ See id.

${ }^{75}$ See id.

${ }^{76}$ OIG Advisory Opinion No. 00-3 (2000) at http://www.oig.hhs.gov/fraud/docs/advisoryopinions/2000/ao00_3.htm.

${ }^{77}$ See discussion supra accompanying note 59.
} 
obstacle in some cases to providing good end-of-life care to terminally ill patients in nursing homes. This seemed to be especially true for patients who were not enrolled in hospice but who may have been receiving the Medicare SNB or were simply receiving custodial care under Medicaid but who could benefit from hospice services in pain management and palliative care. In these cases, some hospice representatives asserted that they had provided the free service in the past, not as an inducement for referrals, but simply because they are committed to providing quality end-of-life care, or as one respondent said, because "it's the right thing to do.",78

As regards concerns about reimbursement and finances, respondents confirmed assertions in the literature that nursing homes perceive that the MHB is financially disadvantageous. At least for some residents, the facility would receive more comprehensive reimbursement under the Medicare skilled nursing benefit (SNB) than it would receive if the resident elected the MHB and the facility received either the state Medicaid per diem or its private pay per diem. ${ }^{79}$

\section{UNINTENDED CONSEQUENCES OF COLLATERAL POLICIES}

For the most part, the government policies and practices discussed, at least as initially conceived, had laudable goals that did not attempt to address inadequate care of the dying. For example, nursing home regulations that encourage improvement in functional level were put in place in response to conditions at many nursing homes which historically did little to engage residents or improve their quality of life but simply served as "way stations" where people were warehoused before death. The regulations were part of the federal Nursing Home Reform Act of 1987 for which advocates for nursing home residents fought hard and long. They have largely

\footnotetext{
${ }^{78}$ While many respondents felt that this provision of the fraud alert negatively affected quality of care, it is not clear whether it may have also affected hospice revenue. In order to know whether hospices were actually providing these bridge services out of quality of care concerns or business concerns it would be helpful to know how much hospices expended on these free services compared to how much they subsequently earned from providing covered hospice services for those patients.

${ }^{79}$ See supra, Reimbursement Issues, pp. 14-18.
} 
been viewed as successful in improving the quality of life for many nursing home residents and should not be displaced or "watered down" for those residents who can benefit from them. Similarly, the fraud and abuse rules were motivated by an effort to combat fraud and the practices of providers who "bilk" the system by providing care that is not warranted or beneficial. Without efforts to control such abuses the underlying integrity of the Medicare and Medicaid programs is threatened.

The reimbursement mechanisms for nursing homes and hospice have at their root goals of efficiency and administrative ease. The per diem payment structures for each bundle together a package of services that have been determined to be necessary for different categories of patients - hospice, skilled nursing, and custodial care. This aggregation of services primarily serves to simplify billing from what otherwise could be an overwhelming administrative task on the part of providers and payers.

Finally, the six month eligibility criteria for hospice was put in place for administrative simplicity as well as to limit costs of the benefit. The goals of Congress in establishing the benefit were dual: to serve as "both a cost-containment mechanism to limit the program's high costs for beneficiaries in their last year of life and a quality improvement tool to improve care for the dying., $" 80$

Despite these valid goals, the policies and practices of the agencies implementing and enforcing them have arguably had the unintended consequence of chilling utilization of hospice services for dying nursing home residents. The incentives created by the constellation of these practices encourage: 1) rehabilitation over palliation, even for dying patients; 2) delayed hospice referral, or 3) no hospice referral or palliative care. Persons with chronic terminal illnesses such as dementia, congestive heart failure, and chronic lung disease, for which it is difficult to predict

\footnotetext{
${ }^{80}$ GAGE ET AL, supra note 1 , at 4.
} 
life expectancy, are particularly disadvantaged by these practices. To the extent that they are referred to hospice, it is likely that they will be referred late in the course of their illness. ${ }^{81}$

\section{SHIFTING THE PARADIGMS}

While the policies and practices at issue were admittedly based on commendable goals, they have at their root assumptions that may not be valid or may be based on incomplete information. The focus of the nursing home regulations on improvement and maintenance of health and function ignores the fact that more and more individuals are dying in long term care facilities. Recent data (2001) from the National Center for Health Statistics indicates that in that year nursing homes were the place of death for over $40 \%$ of individuals over the age of 85 . Moreover, over one-third of all people entering nursing facilities will die within 12 months of admission. ${ }^{82}$ As a result, while regulators should not abandon the goal of physical improvement for nursing home residents who can benefit from aggressive rehabilitation and restoration of function, they can no longer be single minded about this objective. As some have pointed out, this focus "can add greatly to the suffering of a dying resident." ${ }^{83}$ Government policy makers and regulators need to move from a model that focuses on rehabilitation and excludes palliation to one that makes some accommodation for dying individuals.

The paradigm of death as a well defined event, which underlies the hospice benefit's rules and reimbursement criteria requiring an individual to choose between curative and palliative care, also needs to shift to one in which death is recognized as a process during which "mixed management", i.e., both palliative and curative care are appropriate. Such an approach moves away from a model in which these two forms of care are viewed as mutually exclusive to one in which there is a recognition of interventions that can "sometimes prolong life, sometimes

\footnotetext{
${ }^{81}$ Susan C. Miller, et al., Factors associated with the high prevalence of short hospice stays, 6 J. OF PALLIATIVE MED. 725 (2003).

${ }_{83}^{82}$ See NHO REPORT, supra note 34.

${ }^{83} \mathrm{Id}$.
} 
palliate, and sometimes do both." ${ }^{\prime 84}$ The concept is not new and was advocated by the Institute of Medicine in its 1998 report, Approaching Death: Caring at the End-of-Life. ${ }^{85}$ The model that embraces death as a process, also acknowledges that death has different trajectories, some of which are relatively predictable others which are not. The latter has typically included deaths from chronic diseases marked by slow decline "punctuated by crises, one of which may prove fatal." ${ }^{86}$ Health care providers in nursing facilities may understand that individuals in these latter categories have a progressive disease that will lead to death, but they may not see them as dying or as appropriate for hospice.

Finally, we need to adjust the perspective underlying the enforcement of fraud and abuse laws in the context of underutilized services. The OIG's exclusive focus on "over utilization" should shift to one that takes account of inadequate utilization. This does not mean that the OIG should abandon its efforts to root out fraud and abuse but rather that the agency should modify the way it goes about enforcing the fraud and abuse rules in the context of services that are significantly underutilized. In drafting its fraud alert on nursing home/hospice arrangements, the OIG made a number of assumptions about nursing home/hospice behavior that would lead to over utilization without due consideration of the incentives for underutilization.

In the alert, for example, the OIG assumed that nursing home patients were attractive to hospice because they represent "a sizeable pool of potential hospice patients" with longer average lengths of stay than non-institutionalized patients, thus potentially generating higher gross revenues than home care patients in the community. The OIG also asserted that 1) the potential for overlap in services between the two providers creates an opportunity for either provider to reduce services and costs and thereby, under a per diem reimbursement system,

\footnotetext{
${ }^{84}$ InSTITUTE of Medicine, ApProaching DeAth: ImProving CARE AT THE END-OF-LifE (1997) at 84.

${ }^{85}$ Others have advocated this approach as well referring to it as "Medicaring." See Ann M. Wilkinson \& Joann Lynn, "Medicaring: an innovative model of financing and delivery of end-of life care," Critical Issues in Aging (1998). Available at: http://www.asaging.org/am/cia2/mediCaring.html\#annew; see also Ann Wilkinson \& Janet Forlini, MediCaring: quality end-of-life care, 2 J. Health CARE LAW \& POL. 501 (1999).
} 
increase profits/revenues for either or both; 2) if there is more than one hospice patient in a nursing facility the hospice may save costs as a result of economies of scale; and 3) nursing homes have the ability to limit the number of hospices, and choose those hospices, with which they will contract enabling them to hold out for the "highest bidders" or contract only with those that will lead to greater financial remuneration. ${ }^{87}$

While each of these incentives arguably exists, there is evidence that the OIG's assumptions about the providers' behavior in this context may have been based on inaccurate or limited data and have limited generalizability. For example, a 2000 report prepared for DHHS characterized the OIG's assertions of longer hospice lengths of stay in nursing homes as most likely a result of a sampling bias in its survey of hospice programs. ${ }^{88}$ Although there are not definitive data on whether the average hospice length of stay for nursing home patients is greater or less than for patients in the community, recent data suggest that length of stay may be lower than average for patients with certain diagnoses that are more common for nursing home residents such as dementia and other non-cancer conditions as it is often difficult to predict life expectancy for this group. As a result, physicians may not refer to hospice until death is very close at hand. ${ }^{89}$

Moreover, the OIG provides scant evidence for its assertion that hospice or nursing homes may skimp on services because of potential overlap in patient care. While the OIG found

\footnotetext{
${ }^{86}$ INSTITUTE OF MEDICINE, supra note 83 at 28.

${ }^{87}$ OIG Special Fraud Alert, supra note 72 , at 20,416.

${ }^{88}$ See GAGE ET AL., supra note 1, at 27 (stating that the OIG's conclusions regarding average length of stay "are based on an extremely small sample and are most likely influenced by incidence-prevalence bias," and pointing out that "[e]specially in a nursing facility setting, prevalent cases represent more long-stay patients with chronic conditions than do incident cases.").

${ }^{89}$ See Campbell et al., supra note 1, at 275. But see MEDICARE PAYMENT AdVISORY COMM'N, REPORT TO THE CONGRESS: New APPROACHES IN MEDICARE 151 (2004), available at http://www.medpac.gov/publications/congressional_reports/June04_Entire_Report.pdf., at 142 (stating that a recent increase in hospice average length of stay, while the median remained the same, may be due to increased prevalence of nursing home residents in hospice care). Due to the difficulty of predicting life expectancy for many of the illnesses that are prevalent among the nursing home population, it is possible that there is a bimodal distribution of hospice lengths of stay in nursing homes - with a large group of shorter than average length of stay residents and a
} 
in its 1997 report that hospice patients in nursing homes received less nursing, aide and social work visits and more pastoral care visits than those in the community, this was based on data from only 22 hospices and 200 nursing home residents receiving hospice benefits. ${ }^{90}$ In contrast, a recently published study on site of care and hospice visit volume based on data collected in 1998 and 1999 from 21 hospices and 15,484 hospice patients found no "meaningful difference between the total average daily visit volumes in nursing homes versus non-nursing home settings." 91 And, while economies of scale may exist when a hospice has a "critical mass" of patients in a single facility, the cost savings from reduced transportation costs must be balanced with the additional costs to both providers of coordinating care between the two. ${ }^{92}$ As regards the likelihood that nursing homes will cut back services if hospice personnel are caring for their residents, the nursing home regulations are clear that nursing facilities must provide Medicare and Medicaid covered services to all residents regardless of source of payment. ${ }^{93}$

With respect to the OIG's assumption that nursing homes can "pick and choose" among hospices, referring to those that will give them the best "deal," this would depend on the geographic area in which the hospice operates. In many cases, a nursing home has few hospices within its geographic catchment area from which to choose. In some rural areas there may be none or only one hospice within a reasonable distance. While these figures do not obviate concerns about contracting incentives in urban areas, they do call into question the ability of nursing homes in some locations to favor one hospice over another.

small group of greater than average length of stay residents. This latter group, although small, may increase the average length of stay while the median remains approximately the same.

90 See OIG, Hospice PATIENTS, supra note 71, at 6.

${ }^{91}$ Susan C. Miller, Hospice Care in Nursing Homes: Is Site of Care Associated with Visit Volume?, 52 J. Am. GERIATRICS SOC'Y 1331 (2004).

${ }^{92}$ Hospice staff providing care to patients in a nursing home must communicate regularly with both the patient's family and caregivers at the nursing facility and attend regular coordination of care meetings with nursing home staff.

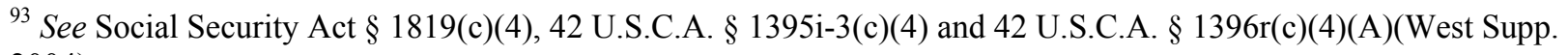
2004). 
In addition to the questionable assumptions underlying the OIG fraud alert, it appears that the OIG may have failed to take account of the more weighty financial and non-financial incentives for nursing homes not to refer residents to hospice. When these other obstacles are taken into account, in particular the financial disincentives to nursing homes for utilization of hospice, ${ }^{94}$ they call into question the hypothetical financial incentives that underlay the fraud alert and suggest that they may not be nearly as important an influence as the perceived barriers and disincentives to hospice utilization.

\section{REALIGNING THE INCENTIVES AND FINDING THE RIGHT BALANCE}

\section{Policies that Recognize that Palliation and Rehabilitation can Coincide}

In its comprehensive report on end-of-life care, published in 1997, the IOM concluded that the "traditional conceptualization" of end-of-life care as encompassing a transition from "cure to care" was too limited and may be disadvantageous to many dying patients. These patients may benefit from a combined approach that incorporates efforts to extend life, either through curative or life prolonging palliative care, with efforts to prepare the patient and his family for the patient's death. The drafters argued that such a combined approach to care "reflects the reality and ideal of end-of-life care in which therapies are not rigidly divided into preventive, curative, rehabilitative, palliative, and other categories but are creatively considered for their potential benefit (or burden) regardless of a patient's prognosis."95

Implementing a policy that embraces both palliation and rehabilitation requires changes to the financial incentives that exist in the current reimbursement system. This can be done through an incremental approach or a wholesale restructuring of the hospice benefit. One incremental approach would be to allow more flexibility under the MHB and provide hospice

\footnotetext{
94 These include the loss of a higher rate of reimbursement if a resident is also eligible for the Medicare skilled nursing benefit.
} 
with lower levels of reimbursement for providing partial benefits to nursing home residents, such as pain management. ${ }^{96}$ This would allow supportive care to persons with terminal illness who may still be receiving treatment. Others have suggested a similar approach, arguing that the exclusive benefits provided under hospice deny some patients needed palliative care. ${ }^{97}$ While the Medicare Prescription Drug, Improvement, and Modernization Act of 2003 (MMA) $§ 512$, provides for separate reimbursement for initial evaluation of pain and symptom management for a non-hospice patient by a hospice physician, the provision does not allow for reimbursement of ongoing consultation or provision of services by hospice staff. ${ }^{98}$

Incentives for patients to elect the skilled nursing benefit over the hospice benefit could also be achieved by providing a room and board benefit to patients in the nursing home who are not eligible for Medicaid and who elect the MHB. This would address the current disparity between the skilled benefit, which covers room and board, and the MHB, which does not, and put the two options on more equal footing when a nursing home resident must decide, after hospital discharge, which benefit to choose. This could be done simply as an add-on to the MHB, which the hospice could pass on to the nursing home, or it could be accomplished by establishing a RUGs category for palliative care. Under this latter alternative, nursing home staff could provide the palliative care or a nursing facility could contract with a hospice to provide the services. While this reimbursement scheme might provide the necessary financial incentive for nursing homes to provide this service, it does not deal with the need for better training of nursing

\footnotetext{
95 Committee on CARE AT The End-OF-Life, Institute of Medicine, ApProAChing DeAth: ImProving CARE AT THE END-OF-LIFE (Marilyn J. Field \& Christine K. Cassel, eds., 1997), at 85.

${ }^{96}$ See Pub. L. 108-173, 117 Stat. 2066 (2003).

${ }^{97}$ See Haiden A. Huskamp et al., Providing Care at the End-of-life: Do Medicare Rules Impede Good Care?, HeAlth AfF., May-June 2001, at 204; see also COMMITTEE ON CARE AT THE END-OF-LIFE, supra note 95.

${ }^{98}$ Nor is the benefit, which went into effect on Jan. 1, 2005, likely to be widely utilized. According to hospice providers, CMS intends only limited use of the provision and will allow it only "when a patient or his physician contacts a hospice agency requesting the evaluation and counseling services." Moreover, CMS has stated that only physicians employed by a hospice can receive payment under the new benefit, "physicians under contract with the hospice are ineligible for the payments." The latter restriction may be a concern by CMS that "[p]ayments by hospice agencies to physicians or others in a position to refer patients. . . may implicate the Federal anti-kickback
} 
home staff in end-of-life care. Any policy change to encourage nursing homes to take on this task must address this issue. ${ }^{99}$

A more fundamental reform would be to establish a new benefit that combines elements of the SNB and MHB. In the commercial insurance market, recognizing that patients and their physicians often have difficulty choosing between palliative and curative care, both Aetna and Kaiser Permanente have recently established a benefit that allows patients who are terminally ill to receive both benefits at the same time. ${ }^{100}$ The need for a more flexible approach to the treatment of dying patients has been recognized by several researchers and practitioners who "point out that as patients become ill and transition toward death, the need for curative care gradually declines and the share of services devoted to palliative care gradually rises; there is no fixed point in time when all care should shift from curative to palliative."101

\section{Tempering Enforcement Actions to Consider Underutilization}

The 1998 fraud alert on nursing home hospice contractual relationships provides an opportunity to examine the OIG's approach to fraud enforcement in the context of underutilized and needed health care services. The utilization of hospice services arguably replicates a pervasive concern in American medicine - one in which evidence that needed services may be provided in an excessive or inappropriate manner by providers who are primarily interested in maximizing their revenues is juxtaposed with evidence that these services are, for a variety of

statute." Providers: CMS Intends to Make Limited Use of New Hospice Benefit, INSIDE CMS (Dec. 16, 2002) available at www.InsideHealthPolicy.com.

${ }^{99}$ The suggestion that nursing homes be required to provide needed end-of-life care was recommended by HCFA in its comments to the OIG on its Sept. 1997 report. In its written comments to the OIG, HCFA responded: "We suggest amending this recommendation to require nursing homes to provide needed end-of-life care; an important safeguard for beneficiaries who actually may need hospice care in a nursing home should the benefit undergo the proposed change .... Your report correctly recommends the reduction or elimination of the hospice benefit in nursing homes, but without requiring nursing homes to provide end-of-life care we would be doing a disservice to our beneficiaries." OIG, HosPiCE PATIENTS, supra note 71, at C-3. The memo further acknowledged that "while many hospice services may be capable of being provided by nursing home staff, many other hospice services (family counseling, bereavement counseling, etc.) probably are not." Id. at C-4.

${ }^{100}$ See MedicARE PAYMENT AdVISORY COMM’N, supra note 89. ${ }^{101} I d$. 
other reasons, not adequately provided to those who need them. While fraudulent actions on the part of any health care provider may negatively affect the "integrity" of the Medicare and Medicaid programs, in the context of "over utilization" of hospice services, the cost to the programs is likely very low while the cost of underutilization of hospice care to dying nursing home residents is arguably very high, i.e., unnecessary pain and suffering at the end-of-life. In this context, efforts to control fraud may actually undermine quality of care or access to care.

The OIG uses fraud alerts "as a vehicle to identify fraudulent and abusive practices within the health care industry." 102 Many of the alerts are disseminated only internally to the OIG's Office of Investigations and other sections of DHHS. However, a number of alerts are also distributed to the general public in "keeping with the OIG's goal and intent of publicizing its concern about possible widespread and abusive health care industry practices." ${ }^{, 103}$ These public alerts are issued relatively infrequently. During the past ten years, only seven such alerts were issued. ${ }^{104}$ The 1998 fraud alert regarding nursing home/hospice contractual relationships was an industry wide alert disseminated broadly to providers and the general public. ${ }^{105}$

As a result of the financial incentives identified by the OIG for nursing homes to enter into contracts with hospice, in its industry wide fraud alert the OIG identified several abusive behaviors, in particular "kickbacks" from hospices to nursing homes to induce referrals to hospice, in which nursing homes and hospices might engage. These included excessive payments for "room and board" (above 100\% of the Medicaid per diem), additional payments for services that the nursing home should already be providing as part of room and board, referring hospice patients to the nursing home, and providing "bridge services" to nursing home patients who are potential hospice patients at rates that are below market value.

\footnotetext{
${ }^{102}$ Publication of OIG Special Fraud Alerts, 59 Fed. Reg. 65,372, 65,372 (Dec. 19, 1994).

${ }^{103} \mathrm{Id}$

${ }^{104}$ See OIG, HHS, Fraud Alerts, Bulletins, and Other Guidance, at http://oig.hhs.gov/fraud/fraudalerts.html (last visited Sept. 14, 2004).

${ }^{105}$ See OIG Special Fraud Alert, supra note 72, at 20,416.
} 
While one could definitely argue that paying nursing homes above $100 \%$ of the Medicaid per diem and paying them for services for which they are already paid under the Medicaid room and board per diem are done with an intent to defraud, the other actions, i.e. referring patients to nursing homes and providing "bridge services," certainly could be done to provide patients with better care. Thus, while some of the actions identified by the OIG would in most cases be clearly fraudulent, as a policy matter it is questionable whether an industry wide alert is necessary or appropriate when: 1) the services at issue are generally underutilized, 2) the incentives for engaging in such actions are low when compared to the disincentives, and 3) when, as a result, only a small fraction of the industry may be engaging is such practices.

Moreover, it would seem appropriate to consider the adverse effects of a broad based (industry wide) alert as compared to a more limited approach that would individually target potential wrongdoers. In the context of nursing home/hospice care, an industry wide fraud alert may undermine broader programmatic goals of providing necessary and beneficial end-of-life care for dying patients and reducing unnecessary Medicare and Medicaid expenditures. ${ }^{106}$

To the extent that the fraud alert further contributed to underutilization of hospice services in the nursing home setting, it may have negatively affected quality of care. A number of studies have shown that many nursing home residents are not receiving adequate end-of-life care, including pain treatment and other symptomatic care. ${ }^{107}$ Furthermore, it is unlikely that patients who, according to the OIG, inappropriately received hospice care were harmed. The additional services provided by hospice would seem to be inherently benign unless one could argue that the individual was being denied services that he/she would otherwise want and need or

\footnotetext{
${ }^{106}$ See GAGE ET AL., supra note 79 and accompanying text.

107 See, e.g., Joan M. Teno et al., Persistent Pain in Nursing Home Residents, 285 J. AM. MED. Ass'N 2081 (2001); Roberto Bernabei et al., Management of Pain in Elderly Patients with Cancer, 279 J. AM. MED. Ass'N 1877 (1998); Bruce A. Ferrell, Pain Evaluation and Management in the Nursing Home, 123 ANNALS INTERNAL MED. 681 (1995); Alice M. Wagner et al., Pain Prevalence and Pain Treatments for Residents in Oregon Nursing Homes, 18 GERIATRIC NURSING 268 (1997).
} 
that discussions about death and dying would have a negative psychological impact upon an individual who is not actively dying.

As regards the second programmatic goal of reducing unnecessary government health care expenditures, while one recently published study found that Medicare expenditures in the last year of life were greater for hospice patients who were older than 84 and who had diagnoses other than cancer, ${ }^{108}$ the study did not specifically address nursing home residents and was limited to Medicare costs. A second, more recently published study, focusing on end-of-life expenditures for nursing home residents, found that overall Medicare and Medicaid spending for dying nursing home residents was not greater for hospice than non-hospice residents and that "overall, total government expenditures in the last month of life were significantly less for hospice versus non-hospice residents." ${ }^{\prime 109}$ Moreover, patients who received the SNB when they could have received the MHB likely cost the Medicare program more than if they had been initially referred to hospice.

The challenge to the OIG is to create rules that deter the small number of providers who are engaging in "fraud" but that do not discourage other providers who are trying to "do the right thing" from providing a necessary and beneficial health service. Achieving the correct balance is certainly not a task uniquely within the domain of the OIG; it applies to all regulators. Yet, with regard to a regulation that is enforceable via criminal penalties, there is arguably a stronger reason to "get the balance right," as the chilling effect of a rule punishable as a crime would seem to be much greater than one with only civil penalties.

In calculating the "right balance" between the joint goals of deterrence of "fraudulent" behavior and adequate provision of health care services, we would argue that the OIG should not only consider the costs associated with over utilization of health care services but also consider

\footnotetext{
${ }^{108}$ See Campbell et al., supra note 1, at 274.
} 
the costs of the effect of rules which "over deter." In the context of use of hospice services by nursing homes, such costs may include those borne by terminally ill residents in nursing homes who are not being adequately treated for their pain or other symptoms, are inappropriately restrained, tube fed, or hospitalized. This may call for a more fine-tuned approach by the OIG generally and consideration of more targeted enforcement and fewer industry-wide fraud alerts. Such broadly targeted pronouncements may have a chilling effect on an entire industry, whose appropriate services, as a policy matter, we do not want to discourage. Moreover, an industry wide approach does not take into consideration variations among different geographic jurisdictions that may affect quality and access to services.

\section{CONCLUSION}

This article sought to examine the government policies and practices that deter hospice use in the long term care setting, the assumptions underlying those policies, and the unintended consequences they have for dying nursing home residents. Given that some of the assumptions at the root of these policies are outdated, unfounded, or based on a failure to take into account the broader context of underutilization of hospice services in nursing homes, we argue for a shift from existing paradigms that encourage rehabilitation and curative care for dying nursing home patients when they may benefit from palliative care; that delay palliative care until the patient can often no longer benefit from such care; and that focus on over utilization to the exclusion of underutilization in the context of enforcement initiatives. In order to address the negative impact of these practices, we call for a restructuring of the existing incentives and an effort to balance (1) the need for rehabilitation with that for palliation; (2) concerns about "overspending" on the hospice benefit with consideration of the overall savings to the health care system from greater use of palliative care; and (3) efforts to weed out fraudulent and abusive over utilization of

\footnotetext{
${ }^{109}$ Susan C. Miller et al., Government Expenditures at the End-of-life for Short-and Long-Stay Nursing Home Residents: Differences by Hospice Enrollment Status, 52 J. AM. GERIATRICS SOC'Y 1284 (2004).
} 
services with the impact of those efforts on undermining broader goals of providing quality endof-life care. 